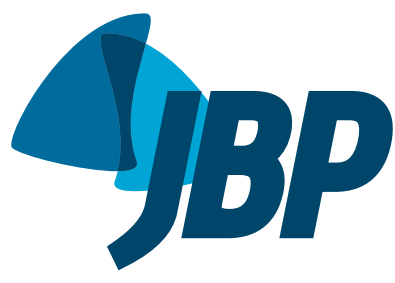

1. Programa de Pós-Graduação em Ciências Médicas, Centro de Ciências da Saúde, Universidade Federal de Santa Catarina, Florianópolis (SC) Brasil.

2. Departamento de Análises Clínicas, Centro de Ciências da Saúde, Universidade Federal de Santa Catarina Florianópolis (SC) Brasil.

3. Departamento de Clínica Médica Centro de Ciências da Saúde, Universidade Federal de Santa Catarina, Florianópolis (SC) Brasil.

a. (iD) http://orcid.org/0000-0003-1919-4274

b. (iD) http://orcid.org/0000-0002-1615-486X

c. iD $h t t p: / / o r c i d . o r g / 0000-0002-3502-9538$

d. (iD $h t t p: / / o r c i d . o r g / 0000-0002-5435-8193$

e. (iD http://orcid.org/0000-0001-7046-9996

f. (iD http://orcid.org/0000-0001-7409-7536

Submitted: 5 May 2017

Accepted: 8 June 2018.

Study carried out at the Departamento de Clínica Médica, Centro de Ciências da Saúde, Universidade Federal de Santa Catarina, Florianópolis (SC) Brasil.

\section{Prevalence of smoking and reasons for continuing to smoke: a population-based study}

\author{
Simone Aparecida Vieira Rocha ${ }^{1, a}$, Andréa Thives de Carvalho Hoepers ${ }^{1, b}$ \\ Tânia Silvia Fröde ${ }^{2, c}$, Leila John Marques Steidle ${ }^{3, d}$, Emilio Pizzichini ${ }^{3, e}$, \\ Márcia Margaret Menezes Pizzichini ${ }^{3, f}$
}

\begin{abstract}
Objective: To investigate the prevalence of smoking and the reasons for continuing to smoke among adults in Brazil. Methods: This was a cross-sectional, population-based study including 1,054 individuals $\geq 40$ years of age, residents of the city of Florianopolis, Brazil, of whom 183 were smokers. All of the smokers completed the University of São Paulo Reasons for Smoking Scale (USP-RSS). Depressive symptoms were evaluated with the Hospital Anxiety and Depression Scale, and spirometry was performed to screen for COPD. Results: Of the 183 smokers, 105 (57.4\%) were female, 138 (75.4\%) were White, and 125 (63.8\%) were in a low economic class. The mean level of education among the smokers was $9.6 \pm 6.1$ years. The mean smoking history was $29 \pm 15$ packyears, $59 \%$ of the men having a $\geq 30$ pack-year smoking history. Approximately $20 \%$ of the smokers had COPD, and $29 \%$ had depressive symptoms, which were more common in the women. The USP-RSS scores were highest for the pleasure of smoking (PS), tension reduction (TR), and physical dependence (PD) domains $(3.9 \pm 1.1,3.6 \pm 1.2$, and $3.5 \pm 1.3$, respectively). Scores for the PS, TR, and weight control (WC) domains were significantly higher in women. Smokers with a $>20$ pack-year smoking history scored significantly higher on the PD, PS, automatism, and close association (CA) domains. Smoking history was associated with the PD, PS, TR, and CA domains. Depressive symptoms were associated with the PD, social smoking, and CA domains $(p=0.001$; $p=0.01 ; p=0.09$, respectively). Female gender and a low level of education were associated with the PS domain $(p=0.04)$ and TR domain $(p<0.001)$. Conclusions: The prevalence of smoking in our sample was relatively high (17.4\%). The USP-RSS domains PS, TR, and WC explain why individuals continue smoking, as do depressive symptoms.

Keywords: Smoking/epidemiology; Tobacco use disorder/psychology; Smoking cessation/ methods; Prevalence.
\end{abstract}

\section{INTRODUCTION}

According to the World Health Organization, smoking is associated with mental and behavioral disorders because of the accompanying dependence on nicotine, which is the main psychoactive substance in tobacco. Nicotine dependence is the primary factor in maintaining smoking behavior among adult smokers. ${ }^{(1)}$ It is well documented that racial and ethnic differences can have a significant influence on the prevalence, patterns, health implications, and consequences of smoking, as well as on the efficacy of smoking cessation interventions. ${ }^{(2)}$

It is estimated that approximately one billion smokers consume six trillion cigarettes annually worldwide and that 10 million individuals will die from smoking-related diseases by 2030. (1) The prevalence of smoking varies across countries, China, India, Indonesia, Russia, the United States, Japan, Bangladesh, Germany, Turkey, and Brazil collectively accounting for over $16 \%$ of all smokers worldwide.
The prevalence of smoking in Brazil varies by region, ranging from $5.1 \%$ in the city of Salvador, located in the northeastern region (in the state of Bahia), to $14.0 \%$ in the city of Curitiba, located in the southern region (in the state of Paraná), and by age group, being higher among adults in the 45- to 64-year age group. ${ }^{(4)}$ In the cities of Fortaleza (located in the northestern region, in the state of Ceará) and Macapá (located in the northern region, in the state of Amapá), the prevalence of smoking is $7.3 \%$ and $8.8 \%$ respectively. In the city of São Paulo (located in the southeastern region, in the state of São Paulo), the prevalence of smoking is $13.2 \%$, compared with $13.6 \%$ and $10.1 \%$, respectively, in the cities of Porto Alegre (in the state of Rio Grande do Sul) and Florianópolis (in the state of Santa Catarina), both of which are in the southern region. ${ }^{(4)}$ It is noteworthy that, regardless of region, the prevalence of smoking in Brazil is higher among males than among females $(12.7 \%$ vs. $8.0 \%){ }^{(4)}$

Correspondence to:

Marcia M M Pizzichini. Departamento de Clínica Médica, Centro de Ciências da Saúde, Universidade Federal de Santa Catarina, Trindade, CEP 88040-970,

Florianópolis, SC. Brasil.

Tel.: 5548 3234-7711. E-mail: marcia.pizzichini6@gmail.com

Financial support: None. 
Understanding the motivations that lead an individual to smoke is relevant because such an understanding can aid in preventing dependence and encouraging smoking cessation. Most previous studies have focused on the motivations to quit smoking, little emphasis having been placed on providing clear information about the motivations to continue smoking. Therefore, the aim of this population-based study was to identify the reasons to continue to smoking among smokers in the southern region of Brazil, through the use of standardized methodology and a validated scale.

\section{METHODS}

This was a cross-sectional, population-based study involving home interviews in the city of Florianopolis and including adults $\geq 40$ years of age. We interviewed current smokers, using questionnaires that have been validated for use in Brazil, ${ }^{(5-8)}$ in order to collect information about their motivations to smoke. The interviews were conducted between April of 2012 and February of 2013. Each interview took, on average, $90 \mathrm{~min}$ to complete. This study was conducted in accordance with the methodology employed in the Latin American Project for Research in Pulmonary Obstruction study ${ }^{(6)}$ and the Respira Floripa (Breathe Floripa) study. ${ }^{(9)}$

The study was approved by the Human Research Ethics Committee of the Federal University of Santa Catarina (Reference no. 1136). All participants gave written informed consent. The research was also conducted in accordance with the principles of the Declaration of Helsinki. ${ }^{(10)}$

The participants were invited to complete the following questionnaires: the Latin American Project for Research in Pulmonary Obstruction/Breathe Floripa questionnaire ${ }^{(6)}$; the Hospital Anxiety and Depression Scale (HADS) ${ }^{(7,8)}$; and the University of São Paulo Reasons for Smoking Scale (USP-RSS). ${ }^{(5)}$

The USP-RSS is a self-report questionnaire that assesses the motivations for smoking. It has been translated to Portuguese, culturally adapted for use in Brazil, and validated for such use. ${ }^{(5)}$ Participants completed the USP-RSS individually. The 21 questions are divided into nine subscales: addiction (items 5-19); deriving pleasure from smoking (items 3-11); tension reduction (items 4, 12, and 18); stimulation (items 1, 9, and 16); automatism (items 7, 14, and 20); handling (items 2-10); social smoking (items 8-15); weight control (items 13-21); and affiliative attachment (items 6-17). Each response is scored on a Likert scale that ranges from 1 to 5 , a score of 1 corresponding to a response of "never" and a score of 5 corresponding to a response of "always". Higher scores indicate greater motivation. The total score quantifies the overall level of motivation, and the subscale scores qualify that motivation. For the purposes of the present study, we established the following factors, hereafter referred to as domains, related the motivations to continue smoking: physical dependence (nicotine dependence); pleasure of smoking (pleasure-seeking); tension reduction (use of cigarettes to relax); stimulus (demand increasing concentration); automatism (smoking without thinking); handling (pleasure derived from manipulating and lighting a cigarette); social smoking (as a facilitator of social interaction); weight control (smoking to lose or maintain weight); and close association ("affiliative attachment" in the original version of the USP-RSS, defined as a strong emotional connection to all experienced situations), ${ }^{(5)}$ the object (e.g., the cigarette) being transformed into a friend.

We evaluated the following variables: the USPRSS scores, gender, race, economic class, level of education, smoking history, diagnosis of COPD (yes or no), and depressive symptoms (yes or no). We excluded smokers who met any of the following criteria: having been diagnosed with a psychiatric disorder that would limit their ability to understand and complete the questionnaire; having a history of longterm institutionalization; having recently undergone surgery; being pregnant; having had angina or acute myocardial infarction in the last three months; having active tuberculosis; and having arterial hypertension.

\section{Sample size}

The sample size calculation was based on the prevalence of COPD in the city of São Paulo, which ranges from $7.8 \%$ to $19.7 \%$ according to data from the study conducted by Menezes et al. ${ }^{(6)}$ The calculation also considered a margin of error of four percentage points and a $20 \%$ margin of safety for non-response and losses. We thus estimated that a sample of approximately 1,000 subjects would be required. To obtain a representative sample that would allow further group analysis, we selected 846 residences housing a collective total of 1,192 individuals. All of the participants who described themselves as smokers were asked to complete the USP-RSS. ${ }^{(5)}$

\section{Sampling procedure}

Given the estimated 1.4 individuals $\geq 40$ years of age per household, we randomly selected 68 of the 419 census tracts in the city of Florianopolis, comprising a total of 846 residences. To obtain a representative sample of adults living in Florianopolis, we applied a cluster sampling strategy, in which economic status (purchasing power, classified as determined by the Brazilian Market Research Association and based on the Brazilian national minimum wage) ${ }^{(11)}$ was specified as follows: class A-heads of households in which the total monthly income is more than 20 times the minimum wage; class $B$-heads of households in which the total monthly income is 10-20 times the minimum wage; class $\mathrm{C}$-heads of households in which the total monthly income is 3-10 times the minimum wage; class D-heads of households in which the total monthly income is 1-3 times the minimum wage; and class $\mathrm{E}$-heads of households in which the total monthly income is equal to or less than the minimum wage. 


\section{Study definitions}

Participants were categorized as smokers if they had smoked at least 100 cigarettes during their lifetime and reported that they were currently smoking at the time of the interview. ${ }^{(12)}$ A diagnosis of COPD was defined by the presence of airflow limitation, as identified by an $\mathrm{FEV}_{1} / \mathrm{FVC}$ ratio $<0.70$ after bronchodilator administration. ${ }^{(13)}$

Because the study design was based primarily on the prevalence of COPD, we included data on symptoms of depression only if the HADS score was $\geq 8$ points. ${ }^{(14)}$ The HADS anxiety data were not considered, because evaluating anxiety was not one of the study objectives.

\section{Methodology}

\section{Spirometry}

Before and after administration of a bronchodilator (albuterol, $200 \mu \mathrm{g}$ ), spirometry maneuvers were performed in accordance with the American Thoracic Society criteria. ${ }^{(15)}$ We employed a portable spirometer (EasyOne; ndd Medical Technologies, Zurich, Switzerland), the calibration of which was checked following the manufacturer's guidelines. All spirometry procedures were analyzed by two pulmonologists with expertise in pulmonary function testing, and the predicted values were calculated from the equations proposed in the National Health and Nutrition Examination Survey. ${ }^{(16)}$

\section{Statistical analysis}

The completed questionnaires were coded by the interviewers and reviewed by the supervisors. Data were selected and double entered into a database. The results are presented as means and standard deviations or as absolute and relative frequencies. The variables were analyzed with Student's t-tests. To compare the means among three or more groups, we used ANOVA. Logistic regression was used in order to analyze descriptive data or to determine whether the various domains or motivational factors for smoking (dependent variable) correlated with the descriptors of interest (independent variables). Odds ratios and their $95 \%$ confidence intervals were calculated for each independent variable. For all analyses, values of $p<$ 0.05 were considered significant. Data were analyzed with the Predictive Analytics Software package, version 18.0 for Windows (SPSS Inc., Chicago, IL, USA).

The study was financed in part by the Coordenação de Aperfeiçoamento de Pessoal de Nível Superior - Brasil (CAPES) - Finance code 001.

\section{RESULTS}

Five of the 846 selected households were not visited because of an inability to contact the residents. Of the 1,192 eligible residents, 110 declined to participate in the study. The remaining individuals $(n=1,082)$ completed all of the steps, corresponding to a response rate of $90.8 \%$. Subsequently, 23 interviews were excluded from the analysis because of participant inability to perform the maneuvers required to obtain reproducible flow-volume curves during spirometry. Therefore, we evaluated 1,059 individuals ( $88.8 \%$ of the eligible population), 188 of whom were categorized as current smokers. Finally, 5 smokers were excluded because they did not answer all of the questions on the USP-RSS. Consequently, the final sample comprised 1,054 individuals, and the prevalence of smoking in the sample was $17.4 \%$.

The sociodemographic and clinical characteristics of the 183 smokers who completed the USP-RSS are detailed in Table 1 . There was a slight, although less than significant, predominance of women, who accounted for $57.4 \%$ of the smokers, which was to be expected because there are more women than men in the city of Florianopolis, as shown in the Brazilian Institute of Geography and Statistics data for 2010.(17) Despite the predominance of female smokers, the number of cigarettes smoked by women, expressed in pack-years, was significantly lower than the number smoked by men, a smoking history greater than 30 pack-years being observed in $59 \%$ of the men, compared with $39 \%$ of the women $(p=0.01)$. Most $(75.4 \%)$ of the smokers reported their race as White. In relation to the economic class, $63.8 \%$ of the smokers were in class $C, 18.6 \%$ were in class $D$ or $E, 8.2 \%$ were in class $A$, and $4.9 \%$ were in class B (Table 1 ). A functional diagnosis of COPD was made in $19.7 \%$ of the smokers evaluated. Symptoms of depression, screened with the HADS depression subscale, were identified in $29.5 \%$ of the smokers, with a significant predominance in women $(p=0.002)$.

Table 2 shows the mean scores for the USP-RSS domains studied. The domains for which the scores were highest were as follows: pleasure of smoking (mean, $3.9 \pm 1.1$ ); tension reduction (mean, $3.6 \pm$ 1.2 ); and physical dependence (mean, $3.5 \pm 1.3$ ). In addition, significant differences were observed between the men and the women in relation to the mean scores for the following domains: pleasure of smoking ( $3.7 \pm 1.3$ vs. $4.1 \pm 1.2, p=0.01)$; tension reduction ( $3.4 \pm 1.2$ vs. $4.0 \pm 1.2, p=0.005)$; and weight control $(1.7 \pm 1.2$ vs. $2.4 \pm 1.6, p=0.002)$.

Individuals with $0-4$ years of schooling had significantly higher scores than did the other participants for the following motivational domains: pleasure of smoking $(p=0.04)$; tension reduction $(p=0.03)$; stimulus $(p=0.001)$; handling $(p=0.009)$; social smoking $(p=0.02)$; and close association $(p=$ 0.001 ). Individuals who reported a smoking history $>21$ pack-years had significantly higher scores for the domains of physical dependence $(p<0.001)$, pleasure of smoking $(p=0.004)$, automatism ( $<<$ $0.001)$, and close association ( $p=0.006)$.

Individuals who presented symptoms or a functional diagnosis of COPD had significantly higher USP-RSS scores than did those without COPD only in the physical dependence domain $(p=0.03)$ and close association domain $(p=0.03)$. Individuals with depressive 
Table 1. Sociodemographic and clinical characteristics of the smokers evaluated.

\begin{tabular}{lc}
\multicolumn{1}{c}{ Characteristic } & (n $=183)$ \\
Age, in years, mean \pm SD & $54.5 \pm 9.2$ \\
Gender, $n(\%)$ & $105(57.4)$ \\
$\quad$ Female & $78(42.6)$ \\
$\quad$ Male & \\
Self-reported race, $n(\%)$ & $138(75.4)$ \\
$\quad$ White & $45(24.6)$ \\
Other & \\
Economic class, $n(\%)$ & $15(8.2)$ \\
A & $9(4.9)$ \\
B & $125(63.8)$ \\
C & $34(18.6)$ \\
D/E & $9.6 \pm 6.1$ \\
Years of schooling, mean \pm SD & $29 \pm 15$ \\
Smoking history, in pack-years, mean \pm SD & $36(19.7)$ \\
COPD, $n$ (\%) & $54(29.5)$ \\
Symptoms of depression, $n(\%)$ &
\end{tabular}

Table 2. University of São Paulo Reasons for Smoking Scale scores, for the sample as a whole and by gender. ${ }^{a}$

\begin{tabular}{lcccc}
\multicolumn{1}{c}{ USP-RSS domain } & $\begin{array}{c}\text { Total } \\
\text { (n }=\mathbf{1 8 3})\end{array}$ & $\begin{array}{c}\text { Male } \\
\text { (n= 78) }\end{array}$ & $\begin{array}{c}\text { Female } \\
(\mathbf{n}=\mathbf{1 0 5})\end{array}$ & $\mathbf{p}^{*}$ \\
\hline Physical dependence & $3.5 \pm 1.3$ & $3.4 \pm 1.3$ & $3.5 \pm 1.3$ & 0.3 \\
Pleasure of smoking & $3.9 \pm 1.1$ & $3.7 \pm 1.3$ & $4.1 \pm 1.2$ & 0.01 \\
Tension reduction & $3.6 \pm 1.2$ & $3.4 \pm 1.2$ & $4.0 \pm 1.2$ & 0.005 \\
Stimulus & $2.5 \pm 1.2$ & $2.3 \pm 1.2$ & $2.6 \pm 1.4$ & 0.3 \\
Automatism & $2.2 \pm 1.2$ & $2.1 \pm 1.1$ & $2.2 \pm 1.1$ & 0.9 \\
Handling & $2.8 \pm 1.3$ & $3.4 \pm 1.3$ & $3.5 \pm 1.3$ & 0.5 \\
Social smoking & $2.2 \pm 1.3$ & $2.1 \pm 1.2$ & $2.2 \pm 1.4$ & 0.5 \\
Weight control & $2.1 \pm 1.5$ & $1.7 \pm 1.2$ & $2.4 \pm 1.6$ & 0.002 \\
Close association & $2.9 \pm 1.4$ & $2.9 \pm 1.3$ & $3.0 \pm 1.4$ & 0.7
\end{tabular}

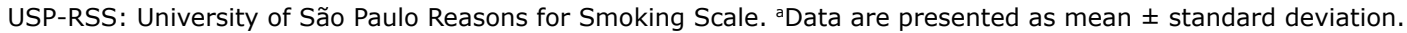
*Unpaired t-test.

symptoms scored significantly higher than did those without on the following domains: physical dependence $(p=0.007)$; tension reduction $(p=0.001)$; stimulus ( $p<0.001)$; social smoking $(p<0.001)$; weight control ( $p=0.01)$; and close association ( $p<0.001)$.

Table 3 shows the results of the logistic regression analysis, performed to evaluate the effects that gender, smoking history, level of education, presence of depressive symptoms, and COPD have on the following domains: physical dependence, pleasure of smoking, tension reduction, stimulus, automatism, handling, social smoking, weight control, and close association. The main determinants of the score for the physical dependence domain were a smoking history of 21-30 pack-years (OR $=15.8 ; 95 \% \mathrm{CI}: 3.9-63.2 ; \mathrm{p}<0.001)$ and the presence of depression symptoms (OR $=3.7$; $95 \% \mathrm{CI}: 1.7-8.1 ; \mathrm{p}=0.001)$. A smoking history $>30$ pack-years was also the main determinant of the scores for the following domains: pleasure of smoking (OR = 5.7; 95\% CI: 2.2-52.7; p > 0.001); tension reduction $(\mathrm{OR}=4.6 ; 95 \% \mathrm{CI}: 1.7-7.4 ; \mathrm{p}=0.006) ;$ and close association (OR $=3.5 ; 95 \% \mathrm{CI}: 1.1-11.2 ; \mathrm{p}=0.02$ ). Depressive symptoms were significantly associated with the physical dependence, social smoking, and close association domains $(\mathrm{p}=0.001, \mathrm{p}=0.01$, and $\mathrm{p}=$ 0.009 , respectively). Female gender and a low level of education were key determinants of the scores for the pleasure of smoking and tension reduction domains ( $p=$ 0.04 and $p<0.001$, respectively). None of the variables studied were found to be determinants of the scores for the domains of automatism and handling ( $p>0.05$ ).

\section{DISCUSSION}

In this population-based study, we employed a robust methodology to evaluate the prevalence and characteristics of smoking, as well as aspects related to the motivations to continue smoking, among individuals 40 years of age or older. Our findings show that the prevalence of smoking was relatively high (17.4\%) in our sample. In addition, our data suggest that low economic class and a low level of education are characteristic of smokers. We also found that, although there were more female smokers than male smokers in our sample, the men had greater smoking histories.

Among the main findings were the fact that the USP-RSS scores were highest for the pleasure of smoking, tension reduction, and physical dependence 
Table 3. Logistic regression analysis of the determinants of the scores for the University of São Paulo Reasons for Smoking Scale domains.

\begin{tabular}{|c|c|c|c|}
\hline $\begin{array}{l}\text { USP-RSS domain } \\
\text { Determinant }\end{array}$ & OR & $95 \% \mathrm{Cl}$ & p* \\
\hline \multicolumn{4}{|l|}{ Physical dependence } \\
\hline \multicolumn{4}{|l|}{ Smoking history } \\
\hline$<10$ pack-years & - & - & - \\
\hline 11-20 pack-years & 6.2 & $(1.6-26.8)$ & 0.009 \\
\hline 21-30 pack-years & 15.8 & $(3.9-63.2)$ & $<0.001$ \\
\hline$>30$ pack-years & 15.1 & $(4.3-52.7)$ & $<0.001$ \\
\hline Symptoms of depression & 3.7 & $(1.7-8.1)$ & 0.001 \\
\hline \multicolumn{4}{|l|}{ Pleasure of smoking } \\
\hline \multicolumn{4}{|l|}{ Smoking history } \\
\hline$<10$ pack-years & - & & - \\
\hline 11-20 pack-years & - & & - \\
\hline 21-30 pack-years & 3.9 & $(1.3-12.0)$ & 0.01 \\
\hline > 30 pack-years & 5.7 & $(2.2-52.7)$ & $<0.001$ \\
\hline Female gender & 2.1 & $(1.0-4.3)$ & 0.04 \\
\hline$\leq 4$ years of schooling & 2.7 & $(1.0-7.0)$ & 0.04 \\
\hline \multicolumn{4}{|l|}{ Tension reduction } \\
\hline \multicolumn{4}{|l|}{ Smoking history } \\
\hline$<10$ pack-years & - & & - \\
\hline 11-20 pack-years & 4.3 & $(1.3-14.4)$ & 0.01 \\
\hline 21-30 pack-years & - & & - \\
\hline > 30 pack-years & 4.6 & $(1.7-7.4)$ & 0.006 \\
\hline Female gender & 3.5 & $(1.0-4.3)$ & $<0.001$ \\
\hline \multicolumn{4}{|l|}{ Level of education } \\
\hline$\leq 4$ years of schooling & 6.6 & $(2.3-18.8)$ & $<0.001$ \\
\hline $5-8$ years of schooling & 4.9 & $(1.7-14.4)$ & 0.004 \\
\hline $9-12$ years of schooling & 4.3 & $(1.5-12.0)$ & 0.004 \\
\hline$\geq 13$ years of schooling & - & & - \\
\hline \multicolumn{4}{|l|}{ Stimulus } \\
\hline$\leq 4$ years of schooling & 5.9 & $(1.2-29.1)$ & 0.03 \\
\hline Symptoms of depression & 3.6 & $(1.4-8.8)$ & 0.006 \\
\hline Automatism & - & - & - \\
\hline Handling & - & - & - \\
\hline \multicolumn{4}{|l|}{ Social smoking } \\
\hline Symptoms of depression & 3.2 & $(1.3-7.7)$ & 0.01 \\
\hline \multicolumn{4}{|l|}{ Weight control } \\
\hline Female gender & 3.4 & $(1.3-9.1)$ & 0.01 \\
\hline \multicolumn{4}{|l|}{ Close association } \\
\hline COPD & 3.2 & $(1.4-7.8)$ & 0.007 \\
\hline Symptoms of depression & 2.7 & $(1.2-5.5)$ & 0.009 \\
\hline > 30 pack-year smoking history & 3.5 & $(1.1-11.2)$ & 0.02 \\
\hline
\end{tabular}

USP-RSS: University of São Paulo Reasons for Smoking Scale.

domains, the scores for the pleasure of smoking, tension reduction, and weight control domains being significantly higher in women. Smokers with a smoking history greater than 20 pack-years scored significantly higher on the physical dependence, pleasure of smoking, automatism, and close association domains. In addition, female gender and a low level of education were key determinants of the scores on the pleasure of smoking and tension reduction domains. For women, the pleasure of smoking, tension reduction, and weight control domains, as well as symptoms of depression, are essential aspects to consider in personalized smoking cessation treatment. The association identified between a greater smoking history and the motivational profile, including the pleasure of smoking, tension reduction, and physical dependence domains, could contribute to the future development of novel smoking cessation strategies.

To our knowledge, this is the first population-based study investigating the reasons to continue smoking among smokers in Brazil. We chose to apply the USP-RSS because it is the result of careful work. As 
previously stated, the USP-RSS has been translated to Portuguese, culturally adapted for use in Brazil, and validated for such use. ${ }^{(5)}$ However, it can be used in other countries, given that it is well constructed and is easily implemented in clinical practice.

The physical dependence, stimulus, handling, social smoking, and close association domains are common to both genders. That could be attributed to the release of mediators in the dopamine reward system. In addition, physical addiction to nicotine may be determined by genes (e.g., the SLC6A3 gene) and dopamine transport, both of which are regulated by the central nervous system. The dopamine D2 and D4 receptor polymorphisms have been shown to be more common in smokers than in nonsmokers. ${ }^{(18,19)}$ In addition, smokers exhibit a significant deficit in dopamine regulation, which requires external stimulus, such as exogenous nicotine, in order to release quantities sufficient to produce pleasurable feelings. ${ }^{(18,19)}$ Other studies have also reported a correlation between nicotine dependence and continued smoking, emphasizing the fact that such dependence is not the only motivational factor for smoking and that more comprehensive studies should be conducted to improve the understanding of the complex relationship between smoking and motivational factors. ${ }^{(20,21)}$

Other relevant findings of the present study were related to the functional diagnosis of COPD and the presence of depressive symptoms. Although the individuals evaluated were aware of the fact that COPD is a serious illness that results in significant pulmonary dysfunction, $19.7 \%$ of the smokers with COPD continued to smoke because they had established an intense emotional link (i.e., a close association) with smoking. In addition, there is evidence that depressed smokers are more motivated to smoke, in order to relieve negative feelings such as anxiety, anger, fear, sadness, and shame. ${ }^{(22,23)}$ Our analysis of the USP-RSS domain scores confirmed those findings.

In the present study, the presence of depressive symptoms, a diagnosis of COPD, and a smoking history greater than 30 pack-years were found to correlate with a close association with smoking. However, our findings should be interpreted with caution, because those factors are influenced by the close relationships among depression, COPD, and smoking. One possible explanation for these findings is that the associations among depressive symptoms, COPD, and smoking history are only a reflection of the physical dependence or depressive symptoms. However, our findings are inconclusive and require further investigation.

We found that social smoking, also known as intermittent smoking, was predominantly associated with depressive symptoms. Although that finding may be due to the age of the individuals in the study sample ( $\geq 40$ years), these are important data that should not be ignored. A recent study describing the motivational profile of adolescents also showed higher scores in the social smoking domain. ${ }^{(24)}$

In the present study, we applied a reliable, validated instrument that provides motivational intensity scores related to smoking in adults. In our sample of 183 smokers $\geq 40$ years of age, we found that the main reasons for continuing to smoke were related to the pleasure of smoking, tension reduction, and physical dependence domains. In addition, we demonstrated some differences between women and men in relation to the determinants of continued smoking. The determinants of the motivational domains pleasure of smoking, stress reduction, and weight control were found to be more common in females. The individual reasons for continuing to smoke identified in this study may contribute to the development of novel targeted smoking cessation strategies.

\section{REFERENCES}

1. World Health Organization [homepage on the Internet]. Geneva: World Health Organization [cited 2017 Nov 6]. WHO report on the global tobacco epidemic, 2011: warning about the dangers of tobacco. [Adobe Acrobat document, 164p.]. Available from: http:// whqlibdoc.who.int/publications/2011/9789240687813_eng.pdf

2. National Center for Chronic Disease Prevention and Health Promotion (US) Office on Smoking and Health. The Health Consequences of Smoking-50 Years of Progress. A Report of the Surgeon General [monograph on the Internet]. Atlanta (GA): US Department of Health and Human Services; 2014 [cited 2017 Aug 15]. Available from: www.ncbi.nlm.nih.gov/books/NBK179276/

3. Aliança de Controle do Tabagismo (ACT) Promoção da Saúde. Dez anos de Convenção-Quadro. ACT: São Paulo; 2015 [cited 2017 Nov 6]. Available from: http://www.actbr.org.br/comunicacao/boletim-actnov2015bn1

4. Brasil. Ministério da Saúde. Secretaria de Vigilância em Saúde Departamento de Vigilância de Doenças e Agravos não Transmissíveis e Promoção de Saúde [homepage on the Internet]. Brasília: o Ministério [cited 2017 Nov 6]. Vigitel Brasil 2016: vigilância de fatores de risco e proteção para doenças crônicas por inquérito telefônico; 2017. [Adobe Acrobat document, 162p.]. Available from: http://portalarquivos.saude.gov.br/images/pdf/2017/junho/07/ vigitel_2016_jun17.pdf

5. Souza ES, Crippa JA, Pasian SR, Martinez JA.University of São Paulo Reasons for Smoking Scale: a new tool for the evaluation of smoking motivation. J Bras Pneumol. 2010;36(6):768-78. https://doi. org/10.1590/S1806-37132010000600015

6. Menezes AM, Victora CG, Perez-Padilla R; PLATINO Team.. The Platino Project: methodology of a multicenter prevalence survey of chronic obstructive pulmonary disease in major Latin American cities. BMC Med Res Methodol. 2004;4:15. https://doi.org/10.1186/1471 2288-4-15

7. World Medical Association. World Medical Association Declaration of Helsinki: ethical principles for medical research involving human subjects. JAMA. 2013;310(20):2191-4. https://doi.org/10.1001/ jama.2013.281053

8. Zigmond AS, Snaith RP. The hospital anxiety and depression scale. Acta Psychiatr Scand 1983;67(6):361-70. https://doi. org/10.1111/j.1600-0447.1983.tb09716.x

9. Karloh M, Rocha SAV, Pizzichini MMM, Cavalli F, Matte DL, Pizzichini E; Respira Floripa Group. Is the COPD Assessment Test sensitive for differentiating COPD patients from active smokers and nonsmokers without lung function impairment? A population-based study. J Bras Pneumol. 2018;44(3):213-219. https://doi.org/10.1590/S180637562017000000149

10. Botega NJ, Bio MR, Zomignani MA, Garcia C Jr, Pereira WA. Mood disorders among inpatients in ambulatory and validation of the anxiety and depression scale HAD [Article in Portuguese]. Rev Saude Publica; 1995;29(5):355-63.

11. Associação Brasileira de Empresas de Pesquisa--ABEP. [homepage 
on the Internet]. São Paulo: ABEP [cited 2018 Nov 1].Critério de Classificação Econômica Brasil. Available from: http://www.abep. org/criterio-brasil

12. Husten CG. How should we define light or intermittent smoking? Does it matter? Nicotine Tob Res. 2009;11(2):111-21. https://doi. org/10.1093/ntr/ntp010

13. Vestbo J, Hurd SS, Agustí AG, Jones PW, Vogelmeier C, Anzueto A, et al. Global strategy for the diagnosis, management, and prevention of chronic obstructive pulmonary disease: GOLD executive summary. Am J Respir Crit Care Med. 2013;187(4):347-65. https:// doi.org/10.1164/rccm.201204-0596PP

14. Miller MR, Hankinson J, Brusasco V, Burgos F, Casaburi R, Coates A, et al. Standardization of spirometry. Eur Respir J. 2005;26(2):319-38. https://doi.org/10.1183/09031936.05.00034805

15. Bjelland I, Dahl AA, Haug TT, Neckelmann D. The validity of the Hospital Anxiety and Hospital Depression Scale. An updated literature review. J Psychosom Res. 2002;52(2):69-77. https://doi. org/10.1016/S0022-3999(01)00296-3

16. Hankinson JL, Odencrantz JR, Fedan KB. Spirometric reference values from a sample of the general U.S. population. Am J Respir Crit Care Med. 1999;159(1):179-87.

17. Instituto Brasileiro de Geografia e Estatística (IBGE) [homepage on the Internet]. Rio de Janeiro: IBGE; [cited 2017 Feb 16]. Pesquisa Nacional de Saúde 2013-Percepção do estado de saúde, estilos de vida e doenças crônicas Brasil, Grandes Regiões e Unidades da Federação. Available from: https://censo2010.ibge.gov.br/sinopse/ webservice/
18. Lerman C, Shields PG, Wileyto EP, Audrain J, Hawk LH Jr, Pinto A, et al. Effects of dopamine transporter and receptor polymorphisms on smoking cessation in a bupropion clinical trial. Health Psychol. 2003;22(5):541-8. https://doi.org/10.1037/0278-6133.22.5.541

19. McClernon FJ, Hutchison KE, Rose JE, Kozink RV. DRD4 VNTR polymorphism is associated with transient fMRI-BOLD responses to smoking cues. Psychopharmacology (Berl). 2007;194(4):433-41. https://doi.org/10.1007/s00213-007-0860-6

20. Boudrez H, De Bacquer D. A Dutch version of the modified reasons for smoking scale: factorial structure, reliability and validity. J Eval Clin Pract. 2012;18(4):799-806. https://doi.org/10.1111/j.13652753.2011.01676.x

21. Piper ME, McCarthy DE, Baker TB. Assessing tobacco dependence: a guide to measure evaluation and selection. Nicotine Tob Res. 2006,8(3):339-51. https://doi.org/10.1080/14622200600672765

22. Covey LS, Glassman AH, Stetner F. Cigarette smoking and major depression. J Addict Dis. 1998;17(1):35-46. https://doi.org/10.1300/ J069v17n01_04

23. Niaura R, Britt DM, Shadel WG, Goldstein M, Abrams D, Brown R. Symptoms of depression and survival experience amons three samples of smokers trying to quit. Psychol Addict Behav. 2001;15(1):13-7. https://doi.org/10.1037/0893-164X.15.1.13

24. Bonilha AG, de Souza ES, Sicchieri MP, Achcar JA, Crippa JA, BaddiniMartinez J. A motivational profile for smoking among adolescents. J Addict Med. 2013;7(6):439-46. https://doi.org/10.1097/01. ADM.0000434987.76599.c0 